\title{
Size and phospholipid coating of lipid droplets in the diet of young mice modify body fat accumulation in adulthood
}

\author{
Annemarie Oosting', Diane Kegler', Harm J. Wopereis ${ }^{2}$, Inga C. Teller', Bert J.M. van de Heijning ${ }^{1}$, Henkjan J.Verkade ${ }^{3}$, \\ and Eline M. van der Beek ${ }^{4}$
}

BACKGROUND: In addition to contemporary lifestyle factors that contribute to the increased obesity prevalence worldwide, early nutrition is associated with sustained effects on later life obesity. We hypothesized that physical properties of dietary lipids contribute to this nutritional programming. We developed a concept infant formula (IMF) with large, phospholipidcoated lipid droplets (Nuturis; Danone Research, Paris, France) and investigated its programming effect on metabolic phenotype later in life.

METHODS: Male C57BI/6j mice were fed a control formula (Control IMF) or Nuturis (Concept IMF) diet between postnatal day (PN)16 and PN42. All mice were subsequently fed a Western-style diet (WSD) until PN126. Body composition was monitored repeatedly by dual-energy X-ray absorptiometry between PN42 and PN126.

RESULTS: Concept IMF slightly increased lean body mass as compared with Control IMF at PN42 but did not affect fat mass. Upon $84 \mathrm{~d}$ of WSD feeding, the Concept IMF group showed reduced fat accumulation as compared with Control IMF. In addition, fasting plasma leptin, resistin, glucose, and lipids were significantly lower in the Concept IMF group.

CONCLUSION: Large phospholipid-coated lipid droplets in young mice reduced fat accumulation and improved metabolic profile in adulthood. These data emphasize that physical properties of early dietary lipids contribute to metabolic programming.

$\mathbf{T}$ he incidence of childhood obesity is rising worldwide $(1,2)$. Because available treatments have only limited success and specifically early-onset obesity increases the risk of early onset of metabolic disease (3), prevention is of the utmost importance. Although evidence is not entirely conclusive, meta-analyses of observational studies have indicated that breastfeeding is associated with a moderately reduced risk of childhood obesity and metabolic disease (reviewed in ref. $4,5)$. The association between infant feeding and long-term metabolic health could be related to early-life growth trajectory: rapid weight gain during infancy has been associated with increased visceral adipose tissue in young children (6) as well as adults (7). Given that rapid weight gain during early postnatal life in infants is associated with specifically fat mass (FM) gain (8) and a higher risk of obesity (7), breastfeeding may protect by moderating early growth. Indeed, breastfeeding has been shown to result in lower weight-for-length and FM from 7 mo onward as compared with formula feeding (9). Taken together, these data suggest that infant nutrition affects the early development of adipose tissue and has a sustained impact on body composition later in life.

The sustained protective effects of breastfeeding on obesity and metabolic health later in life are probably multifactorial and could include feeding regimen, maternal behavior, mode of food delivery, and nutritional composition (10). Human milk (HM) contains both nutrients and bioactive compounds, including endocrine and immune factors, securing healthy growth and development during infancy (11-13). Dietary lipids are a key source of energy and essential nutrients during infancy. A comparison between lipids in mature HM and those in current infant milk formulas (IMFs) shows differences in lipid classes (14), fatty acid (FA) composition (15), and physical structure (16). HM lipid globules are secreted from the mammary epithelial cells through exocytosis into the alveolar lumen. This process produces droplets with a core consisting of triglycerides and cholesteryl-esters surrounded by a native milk fat globule membrane composed mainly of phospholipids (PLs), proteins and enzymes, free cholesterol, and glycoproteins. The lipid droplet size ranges between 1 and $10 \mu \mathrm{m}$, with an average mode diameter of $4 \mu \mathrm{m}$ in mature milk (17). In contrast, lipid droplets produced during processing of IMF have a diameter of $\sim 0.3-1.0 \mu \mathrm{m}$ and consist of a triglyceride core with milk proteins adhering to the globule surface (16).

We hypothesized that the specific surface composition and size of the lipid droplets in HM contribute to the long-term benefits of breast-feeding on metabolic health later in life. To test this hypothesis, we developed a concept IMF with lipid droplets with physical properties similar to those in HM, i.e., larger in size and coated with PLs (Nuturis; Danone Research, Paris, France). We compared this concept IMF with a control IMF in a mouse model of nutritional programming (18). A diet containing either control or concept IMF was provided

'Department of Developmental Physiology \& Nutrition, Danone Research, Centre for Specialised Nutrition, Wageningen, The Netherlands; ${ }^{2}$ Department of 
for $26 \mathrm{~d}$ in early life, after which all mice were fed a "moderate" Western-style diet (WSD; 10\% w/w fat and 0.1\% w/w cholesterol) for $84 \mathrm{~d}$ during adolescence and adulthood. We subsequently determined the effects of the control and concept IMF in early life on adult body composition and metabolic health.

\section{RESULTS}

\section{IMF Analyses}

IMF processing and addition of $2 \mathrm{~g} / \mathrm{l}$ PLs from buttermilk serum powder resulted in the Concept IMF (Nuturis) with PL-coated lipid droplets (Figure 1). A clear shift was observed toward larger lipid droplets in the Concept IMF as compared with Control IMF (Figure 2). In the Concept IMF, more than $50 \%$ of the total volume of lipid particles was present in droplets with a diameter ranging between 2 and $12 \mu \mathrm{m}$. Less than $35 \%$ of the volume was present in particles with a diameter of $2 \mu \mathrm{m}$ or smaller. In contrast, $<15 \%$ of the particle volume was represented in droplets with a diameter between 2 and $12 \mu \mathrm{m}$ in the Control IMF, and $85 \%$ of the total volume was present in the droplets of $<2 \mu \mathrm{m}$. Peak diameter of the particle size distribution was 0.40 and $6.25 \mu \mathrm{m}$ in the Control and Concept IMF, respectively (Figure 2). FA composition was comparable in Concept
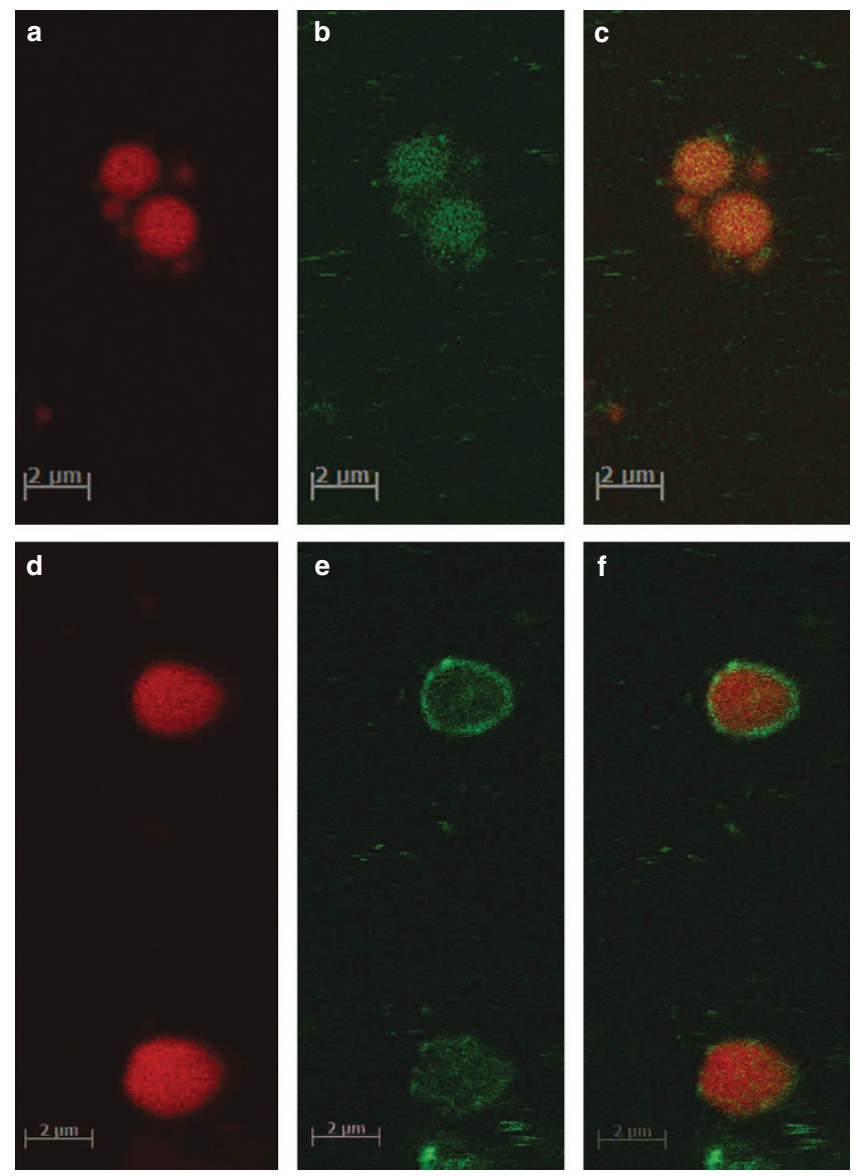

Figure 1. Images of confocal laser scanning microscopy of (a,d) Nile Redstained fat core, (b,e) Annexin-V Alexa Fluor 488-stained PL coating, and (c,f) dual staining of Control IMF and Concept IMF, respectively. Original magnification, $\times 4,250$, bar $=2 \mu \mathrm{m}$. IMF, infant milk formula. and Control IMF. PL content of Concept IMF was $3.6 \mathrm{~g} / \mathrm{kg}$ as compared with $0.1 \mathrm{~g} / \mathrm{kg}$ in the Control IMF diet (Table 1).

Direct effects of IMF-based diets on growth and body composition. An early intervention with Concept IMF resulted in a $8 \%$ higher lean body mass (LBM) at postnatal day (PN) 42 $\left(\mathrm{t}_{(20)}=5.417, P=0.031\right)$ as compared with Control IMF directly after intervention (Figure 3a). In contrast, FM $\left(\mathrm{t}_{(20)}=0.007\right.$, $P=0.936)$ and body weight $(\mathrm{BW})\left(\mathrm{t}_{(20)}=1.429, P=0.246\right)$ were similar in the two groups.

Programming effects of IMF-based diets on food intake, $B W$ gain, and body composition development. Average food intake from PN42 to PN126 was comparable between groups $(12.7 \pm 0.3$ and $13.1 \pm 0.4 \mathrm{kcal} / \mathrm{d} /$ animal for the Control and Concept IMF groups, respectively). To distinguish between direct and programming effects of early diet on development later in life, we calculated absolute values of BW, LBM, FM, and $\% \mathrm{FM}$ as well as relative changes, indicated as delta values (i.e., delta (d)BW, dLBM, dFM, d\%FM) during WSD challenge (Figure 3b). During WSD challenge from PN42 to PN126, BW gain was $17 \%$ lower in the Concept IMF as compared with the Control IMF group $\left(\mathrm{F}_{(2,40)}=4.630, P=0.016\right)$. However, differences were moderate as post hoc analyses could not confirm significant differences in $\mathrm{dBW}$ at individual time points.

Relative LBM gain during WSD was similar in the Control and Concept IMF groups ( $\left.\mathrm{dLBM} \mathrm{F}_{(1,20)}=0.079, P=0.978\right)$. In contrast, fat mass development in adolescence and adulthood was affected by early postnatal diet. Both FM $\left(\mathrm{F}_{(3,60)}=\right.$ $2.974, P<0.039)$ and $\% \mathrm{FM}\left(\mathrm{F}_{(3,60)}=3.914, P=0.013\right)$ gain after WSD challenge were lower in animals previously fed Concept IMF as compared with animals fed Control IMF $\left(\mathrm{F}_{(3,60)}=2.974\right.$, $P=0.039)$. Post hoc analyses of individual time points confirmed a 24 and 28\% lower dFM in the Concept IMF group as compared with the Control IMF group at PN98 and PN126, respectively. In addition, d\%FM was 31,30 , and $28 \%$ lower in the Concept IMF group as compared with the Control IMF group at PN70, PN98, and PN126, respectively.

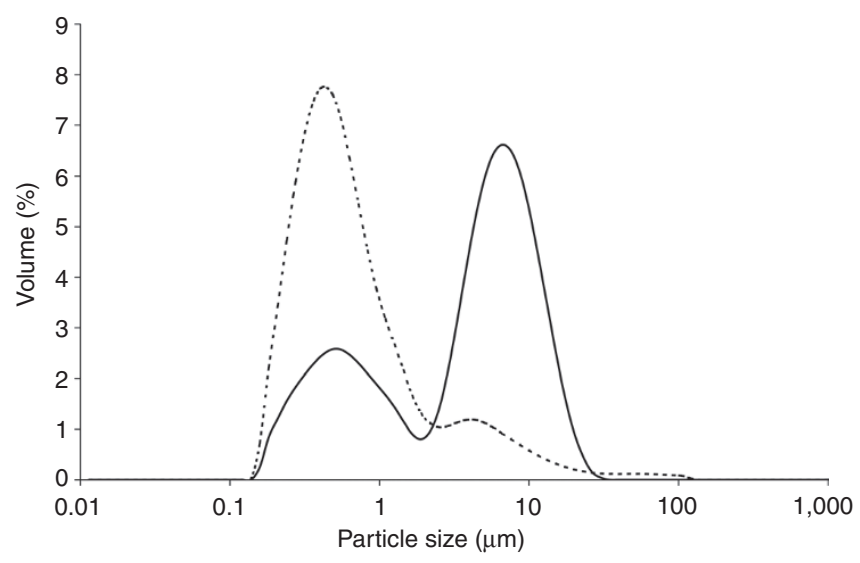

Figure 2. Particle size distribution of control (dashed line) and concept IMF (solid line). IMF, infant milk formula. 
Table 1. Composition of the experimental diets

\begin{tabular}{|c|c|c|c|c|}
\hline & \multicolumn{2}{|c|}{ Postnatal IMF diet } & \multirow[b]{2}{*}{ WSD } \\
\hline & & Control & Concept & \\
\hline Carbohydrates & $(g / k g)$ & 645 & 645 & 600 \\
\hline Sugars & $(\mathrm{g} / \mathrm{kg})$ & 235 & 235 & 150 \\
\hline Dextrose & $(g / k g)$ & 5 & 5 & 150 \\
\hline Lactose & $(\mathrm{g} / \mathrm{kg})$ & 145 & 145 & 0 \\
\hline Sucrose & $(\mathrm{g} / \mathrm{kg})$ & 85 & 85 & 0 \\
\hline Polysaccharides & $(g / k g)$ & 410 & 410 & 450 \\
\hline Maltodextrine & $(g / k g)$ & 50 & 50 & 250 \\
\hline Starch & $(\mathrm{g} / \mathrm{kg})$ & 360 & 360 & 200 \\
\hline Protein & $(g / k g)$ & 179 & 179 & 179 \\
\hline Soy & $(\mathrm{g} / \mathrm{kg})$ & 150 & 150 & 179 \\
\hline Whey & $(g / k g)$ & 17 & 17 & 0 \\
\hline Casein & $(g / k g)$ & 12 & 12 & 0 \\
\hline Fat & $(\mathrm{g} / \mathrm{kg})$ & 70 & 70 & 100 \\
\hline Oil blend ${ }^{a}$ & $(g / k g)$ & 69.1 & 53.0 & 50 \\
\hline Milk fat & $(\mathrm{g} / \mathrm{kg})$ & 0.9 & 17.0 & 0.0 \\
\hline Lard & $(\mathrm{g} / \mathrm{kg})$ & 0 & 0 & 50 \\
\hline Saturated fatty acids & $(\mathrm{g} / \mathrm{kg})$ & 28.5 & 31.4 & 41.9 \\
\hline Monounsaturated fatty acids & $(g / k g)$ & 30.5 & 28.8 & 42.3 \\
\hline Polyunsaturated fatty acids & $(g / k g)$ & 11.0 & 9.8 & 13.2 \\
\hline Linoleic acid (LA) & $(g / k g)$ & 9.3 & 8.4 & 11.9 \\
\hline a-Linolenic acid (a-LA) & $(g / k g)$ & 1.7 & 1.5 & 1.3 \\
\hline LA/aLA & $(g / k g)$ & 5.5 & 5.7 & 9.5 \\
\hline Phospholipids ${ }^{\mathrm{b}}$ & $(g / k g)$ & 0.1 & 3.6 & 0.0 \\
\hline Cholesterol & $(\mathrm{mg} / \mathrm{kg})$ & 4.7 & 65 & 1,000 \\
\hline Cellulose (Vitacel L 600-20) & $(g / k g)$ & 50 & 50 & 50 \\
\hline Mineral mix & $(\mathrm{g} / \mathrm{kg})$ & 35 & 35 & 35 \\
\hline Vitamin mix & $(\mathrm{g} / \mathrm{kg})$ & 10 & 10 & 10 \\
\hline Choline bitartrate & $(\mathrm{g} / \mathrm{kg})$ & 2.5 & 2.5 & 2.5 \\
\hline L-Cysteine & $(\mathrm{g} / \mathrm{kg})$ & 3 & 3 & 3 \\
\hline Tert-butylhydroquinone & $(\mathrm{g} / \mathrm{kg})$ & 0.014 & 0.014 & 0.014 \\
\hline
\end{tabular}

IMF, infant milk formula.

aMixture of oils, among others canola, sunflower, fish, coconut, and palm oil.

bPhospolipids (phosphatidyl choline, 31.1\%; phosphatidyl ethanolamine, 24.6\%; sphingomyelin, 19.7\%; phosphatidyl serine, 11.5\%; phosphatidyl inositol, 6.6\%)

were derived from buttermilk serum powder (35.5\% lactose, $28.5 \%$ protein, $23.5 \%$ fat).

Organ weight. Weights of white adipose tissue depots at PN126 were only moderately affected by postnatal diets (Table 2) and subsequent WSD (data not shown). Comparison of the Control and Concept IMF groups did not show significant differences in white adipose tissue depot or organ weight.

Plasma parameters. Plasma adiponectin, monocyte chemoattractant protein 1, total plasminogen activator inhibitor-1, interleukin 6, and tumor necrosis factor a did not differ significantly between the two groups at PN126 (Table 3). However, plasma leptin $\left(\mathrm{t}_{(24)}=2.324, P=0.029\right)$ and resistin $\left(\mathrm{t}_{(23)}=1.913\right.$, $P=0.037)$ were significantly lower in the Concept IMF group as compared with the Control IMF group. At PN126, fasting triglycerides $(\mathrm{TG})\left(\mathrm{t}_{(25)}=3.438, P=0.002\right)$ and total cholesterol (TC) $\left(t_{(29)}=2.627, P=0.014\right)$ levels were lower in the Concept IMF group as compared with the Control IMF group. Moreover, glucose homeostasis during fasting was different due to early postnatal diet, with a significant lower plasma glucose $\left.\mathrm{t}_{(24)}=2.531, P=0.018\right)$ and homeostasis model assessment of insulin resistance $\left(\mathrm{t}_{(25)}=1.741, P=0.047\right)$ in Concept IMF-fed as compared with Control IMF-fed animals. Fasting insulin was similar in the two groups.

\section{Effect of WSD Challenge During Adolescence and Adulthood}

Average food intake from PN42 to PN126 was comparable between the nonchallenged reference $(12.6 \pm 0.4 \mathrm{kcal} / \mathrm{d} /$ animal) and WSD-challenged groups.

Both absolute BW and LBM gain from PN42 to PN126 was comparable between the nonchallenged reference group and both WSD-challenged (Control and Concept IMF) groups. FM and \%FM gain was 51 and $73 \%$, respectively, higher in the Control IMF group as compared with the nonchallenged reference group. In contrast, FM did not differ significantly between Concept IMF group fed WSD from PN42 to PN126 and the nonchallenged reference group (data not shown). Between PN98 and PN126, FM gain in both WSD-challenged groups decreased, resulting in \%FM values closer to the values of nonchallenged reference mice (data not shown). In addition, fasting plasma TG and TC were increased due to WSD in adolescence and adulthood (TG: $0.25 \pm 0.02$ vs. $0.57 \pm$ $0.02 \mathrm{mmol} / \mathrm{l}$, TC: $2.44 \pm 0.24$ vs. $3.48 \pm 0.20 \mathrm{mmol} / \mathrm{l}$ in nonchallenged reference and Control IMF groups, respectively). In contrast, plasma adipokines and glucose homeostasis were unaffected by adult WSD.

\section{DISCUSSION}

This study strongly suggests that physical properties of dietary lipids contribute to body composition and metabolic health later in life. Besides distinct differences in FA composition and lipid classes, HM and IMF show a clear difference in the physical structure of lipids: raw milk lipid droplets are larger and coated with a native milk fat globule membrane as compared with lipid droplets in infant formula, which are predominantly covered with milk proteins (16).

The most striking and sustained effect of the altered postnatal diet with a lipid structure closer to that of human milk was the difference in FM gain and improved metabolic profile once switched to the WSD diet. Absolute and relative FM were similar in all groups directly following the diet intervention at PN42, but postnatal Nuturis reduced the fat percentage increase due to the WSD challenge by $\sim 30 \%$.

The amount of body fat is strongly related to the prevalence of cardiometabolic risk factors both in children (19) and adults (20), indicating that reducing FM reduces disease risk. Evidence from clinical studies showed that $5 \%$ reduction in body fat percentage improved cardiometabolic risk profile in obese children (21) and adults (22). Very few experimental studies have focused on prevention of obesity and metabolic 

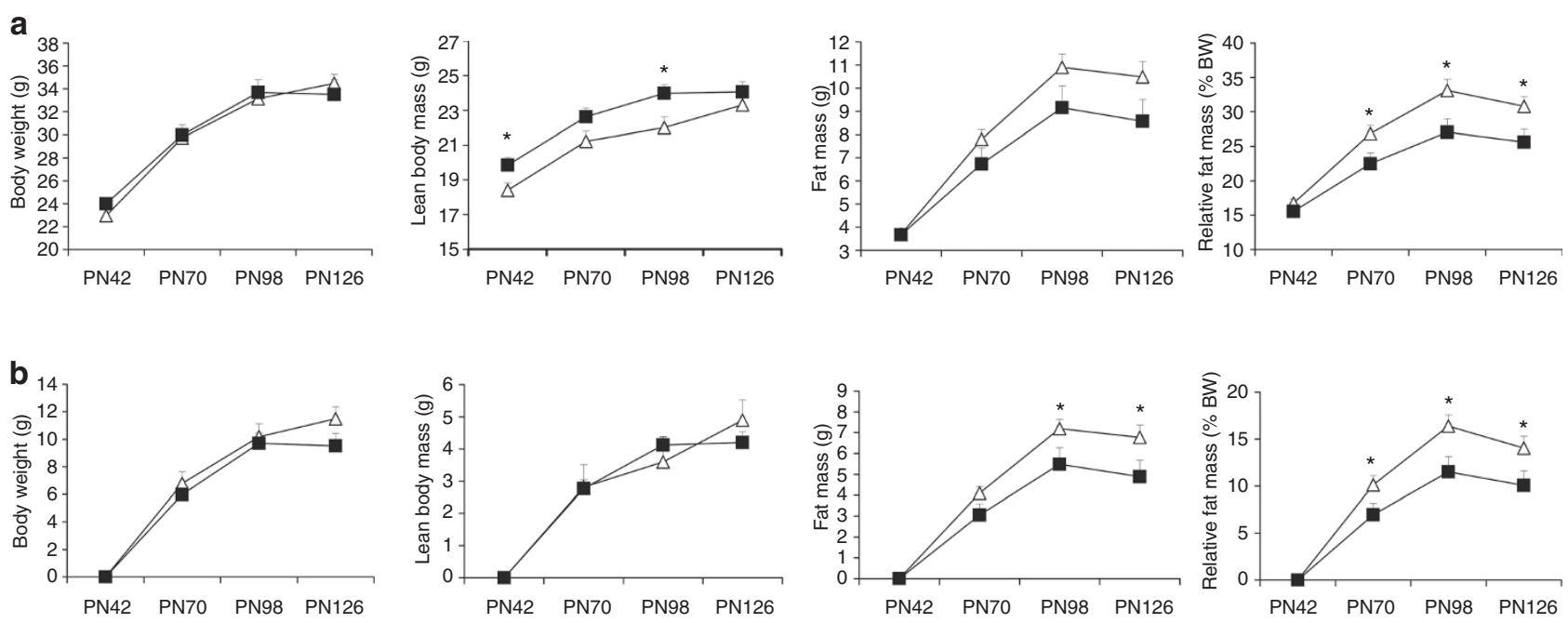

Figure 3. Body composition development during WSD challenge (PN42-PN126) of mice fed Control IMF (open triangles) or Concept IMF (filled squares) until PN42. (a) Body weight (BW), lean body mass (LBM), fat mass (FM), and relative fat mass (\%FM); (b) values relative to baseline (PN42): delta (d)BW, $\mathrm{dLBM}, \mathrm{dFM}$, and d\%FM; $n=10-12$ group; $* P<0.05$. PN, postnatal day; WSD, Western-style diet.

Table 2. Average weight of WAT depots and organs at PN 126 of mice fed Control $(n=10)$ or Concept IMF $(n=14)$ before WSD

\begin{tabular}{llcc}
\hline & & Control IMF & Concept IMF \\
\hline \multirow{2}{*}{ WAT } & Epididymal (g) & $1.4 \pm 0.1$ & $1.3 \pm 0.1$ \\
& Retroperitoneal (mg) & $379 \pm 32$ & $349 \pm 36$ \\
Liver (g) & Inguinal (mg) & $772 \pm 44$ & $666 \pm 51$ \\
Pancreas (mg) & $1.57 \pm 0.1$ & $1.6 \pm 0.1$ \\
Musculus tibialis (mg) & $174.2 \pm 12.8$ & $174 \pm 13$ \\
Brain (mg) & $94.3 \pm 2.1$ & $94 \pm 2$ \\
\hline
\end{tabular}

IMF, infant milk formula; PN, postnatal day; WAT, white adipose tissue; WSD, Westernstyle diet.

disease by nutrients in early life. Most studies on nutritional programming have investigated factors in the fetal and/or postnatal environment that predispose to disease (reviewed in ref. 23) rather than to prevention of disease. In addition, subsequent postnatal exercise (24) and pharmacological interventions (25) ameliorated adverse metabolic phenotype caused by intrauterine growth retardation, indicating that early postnatal life is a critical period in development. Few studies have shown that exposure to $n 3$ long-chain polyunsaturated fatty acids throughout life protects against the detrimental effects of an adverse fetal environment on blood pressure, inflammation, leptin sensitivity, and glucose homeostasis in adult rats $(26,27)$. In addition, $n 3$ long-chain polyunsaturated fatty acid supplementation during pregnancy and lactation reduced BW of adult rat offspring on a standard chow by $5 \%$ (28). In accordance, we have shown previously that $5 \% \mathrm{n} 3$ long-chain polyunsaturated fatty acids in the postnatal diet of mice lowers adult FM by $28 \%$ upon $56 \mathrm{~d}$ of WSD feeding (18). The magnitude of this nutritional programming effect on adult FM closely resembles that of
Table 3. Average fasting plasma parameters at PN 126 of mice fed Control $(n=10)$ or Concept IMF $(n=14)$ before WSD

\begin{tabular}{llcc}
\hline & & Control IMF & Concept IMF \\
\hline & Adiponectin $(\mathrm{mg} / \mathrm{l})$ & $8.95 \pm 0.55$ & $7.75 \pm 0.50$ \\
& Leptin $(\mu \mathrm{g} / \mathrm{l})$ & $1.48 \pm 0.16$ & $1.26 \pm 0.17^{*}$ \\
& Resistin $(\mu \mathrm{g} / \mathrm{l})$ & $1.55 \pm 0.09$ & $1.34 \pm 0.05^{*}$ \\
& MCP-1 $(\mathrm{ng} / \mathrm{l})$ & $22.1 \pm 5.0$ & $19.1 \pm 3.4$ \\
& tPAl-1 $(\mu \mathrm{g} / \mathrm{l})$ & $2.04 \pm 0.19$ & $2.29 \pm 0.48$ \\
& TNF-a $(\mathrm{ng} / \mathrm{l})$ & $10.3 \pm 6.8$ & $5.05 \pm 1.0$ \\
Glucose & IL-6 $(\mathrm{ng} / \mathrm{l})$ & $8.57 \pm 2.3$ & $22.04 \pm 10.1$ \\
homeostasis & Insulin $(\mathrm{pmol} / \mathrm{l})$ & $257.3 \pm 28.0$ & $219.2 \pm 45.8$ \\
& HOMA-IR $((\mathrm{mmol} / \mathrm{l} \times$ & $148.8 \pm 20.0$ & $102.5 \pm 17.7^{*}$ \\
& pmol/l)/22.5) & & \\
Lipids & Triglycerides (mmol/l) & $0.57 \pm 0.02$ & $0.42 \pm 0.04^{*}$ \\
& Total cholesterol & $3.48 \pm 0.20$ & $2.68 \pm 0.23^{*}$ \\
\hline
\end{tabular}

HOMA-IR, homeostasis model assessment of insulin resistance; IL-6, interleukin 6; IMF, infant milk formula; MCP-1, monocyte chemoattractant protein-1; PN, postnatal day; TNF-a, tumor necrosis factor-a; tPAl-1, total plasminogen activator inhibitor-1;WSD, Western style diet.

${ }^{*} P<0.05$ as compared with Control IMF.

our present study, which investigated a postnatal diet with distinct physical and compositional lipid properties without any significant change in FA composition.

Early postnatal life is considered a critical period in development of the metabolic system and programs its functionality and metabolic homeostasis later in life (29-31). For instance, development of the endocrine pancreas continues until $4 \mathrm{y}$ after birth in humans and its structure and functionality is affected by nutrition during both fetal and postnatal life $(32,33)$. Adult adipocyte number in white adipose tissue, another key endocrine tissue in metabolism, is also set during 
early life (34) and is affected by dietary FA (35). Other lipid components may also play a role. For example, dietary cholesterol in infancy affects adult cholesterol metabolism $(36,37)$. Moreover, postnatal supplementation of a milk fat globule membrane fraction containing bioactive lipids such as phospholipids, gangliosides, and other polar lipids enhanced BW gain and improved brain function in young rats (38). Thus, dietary lipids during this sensitive period can influence the development of organ structures and physiological systems and thus their functionality.

The mechanism underlying the nutritional programming effects of Nuturis found in this study remains elusive. Metabolic development may have been modulated by differences in absorption and digestion kinetics. In adults, small lipid droplets from a fat emulsion were hydrolyzed faster than larger lipid droplets (39), whereas small IMF lipid droplets without a PL coating were hydrolyzed more slowly in preterm infants than large HM milk lipid droplets with a native membrane (40). This suggests that (i) size and surface composition play a differential role in digestion kinetics and (ii) these are differentially handled in early childhood and adulthood. It has been shown in rats that these physical properties also modulate plasma triglyceride appearance (41) and $\beta$-oxidation rate (42). Taken together, these studies indicate that differences in lipid digestion and absorption could influence utilization of these lipids for either $\beta$-oxidation or lipogenesis. Whether this is also true for the Concept IMF in this study and whether this affected early growth rate remain to be investigated. Unfortunately, the experimental design did not allow recording of preweaning food intake and body weight gain per individual pup, which limits our understanding concerning direct effects of the Concept IMF on early growth. Future studies are required to confirm our hypothesis and acquire more insight into modulation of early growth trajectories by physical properties of lipids in infant nutrition.

The observed adult phenotype appeared to be dependent on age and/or diet challenge: at PN126, FM gain reduced in both challenged groups, as did the difference between the initially divergent FM gains in the Control and Concept IMF groups. The results do not confirm whether the Concept IMF programs toward delayed ("slower") fat accumulation or rather toward a sustained reduced fat accumulation during aging. The WSD challenge was very mild as compared with obesogenic models using diets with $45-60 \%$ energy from fat $(43,44)$ to model for mild obesogenic dietary patterns of many Western and developing countries. However, the WSD was even relatively moderate as compared with a diet resembling human Western dietary fat intake (45) and was therefore insufficient to sustain an adverse metabolic phenotype as compared with the nonchallenged reference group. To be able to conclude that the Concept IMF either delays, reduces, or prevents excessive fat accumulation later in life, future studies should include a more severe obesogenic diet.

As food intake during adulthood was similar between groups, the reduced FM in Concept IMF mice cannot be explained by a difference in energy intake. The moderately higher LBM in Concept IMF mice at PN42 and after WSD at PN126 indicates a different utilization of nutrients as compared with Control IMF mice. This shift may direct toward development of LBM rather than FM, ultimately resulting in a different growth trajectory.

The improved adult body composition in the Concept IMF group was accompanied by an improved metabolic profile, as shown by lower fasting plasma TG, TC, and glucose concentrations as compared with the Control IMF group. Given that systemic adipokine levels were not significantly perturbed by the moderate WSD challenge as compared with normal rodent chow, the limited improvement in adult adipokine profile due to Concept IMF was to be expected. However, lower plasma leptin and resistin in the Concept IMF group suggest an improved metabolic profile as compared with Control IMF given that leptin is correlated with FM, resistin is associated with insulin resistance, and both are increased in obese adolescent subjects (46).

In conclusion, this study underlines that lipid structure, e.g., large, PL-coated lipid droplets, in postnatal diet reduces fat accumulation and improves metabolic profile in mice during adolescence and adulthood. Our data suggest that protective effects of breastfeeding may be partly explained by the physical properties of lipids in HM. Taken together, it is becoming apparent that not only dietary FA composition (e.g., essential FA and long-chain polyunsaturated fatty acid content) but also physical properties of dietary lipids contribute to dietary lipid quality and play a role in programming of adult metabolic health. Future studies should investigate how distinct features of lipid quality, for instance, lipid composition and physical lipid structure, interact.

\section{METHODS}

\section{Animals and Study Design}

All experimental procedures were approved by the Animal Experimental Committee DEC-Consult, Bilthoven, The Netherlands, and complied with the principles of good laboratory animal care. Mice were housed at facilities of the Wageningen University and Research Centre (Wageningen, The Netherlands) on a 12/12 h light/dark cycle (light on $06: 00 \mathrm{~h}=$ Zeitgeber time $0 \mathrm{~h}$ ) in a temperature- and humidity-controlled room $\left(21 \pm 2{ }^{\circ} \mathrm{C}\right.$ and $50 \pm 5 \%$, respectively). Food and water were available ad libitum during the entire experimental protocol, except before blood sampling when animals were fasted for at least $4 \mathrm{~h}$ during the light phase (from 7:30 AM onward). Food intake was measured per cage biweekly from PN42 onward. Individual food intake could not be measured before PN42, because the diets were presented in the form of dough in the cage and were provided to the dam and litters from PN16 onward. BW was measured per litter before weaning at PN2, PN7, PN14, and PN21 and individually after weaning on a weekly basis. Male and female C57Bl/6j mice were fed standard semi-synthetic rodent chow upon arrival and timemated. After birth, litters were culled to four male and two female pups per dam on PN2 and randomly assigned to diet containing a control IMF (Control IMF) or to the Nuturis concept IMF (Concept IMF) from PN16 onward. Pups had access to their respective diets but were also allowed to drink milk until weaning at PN21 when male pups were housed in pairs and continued their respective diets until PN42. Subsequently, male pups of the Control IMF and the Concept IMF groups changed to a moderate WSD $(10 \% \mathrm{w} / \mathrm{w}$ fat) during their adolescence and adulthood until dissection on PN126 (Figure 4). To confirm effectiveness of the WSD challenge in adolescence and adulthood, we included a separate nonchallenged reference group, which was maintained on a standard semi-synthetic rodent chow (AIN93) during the entire experimental protocol. 


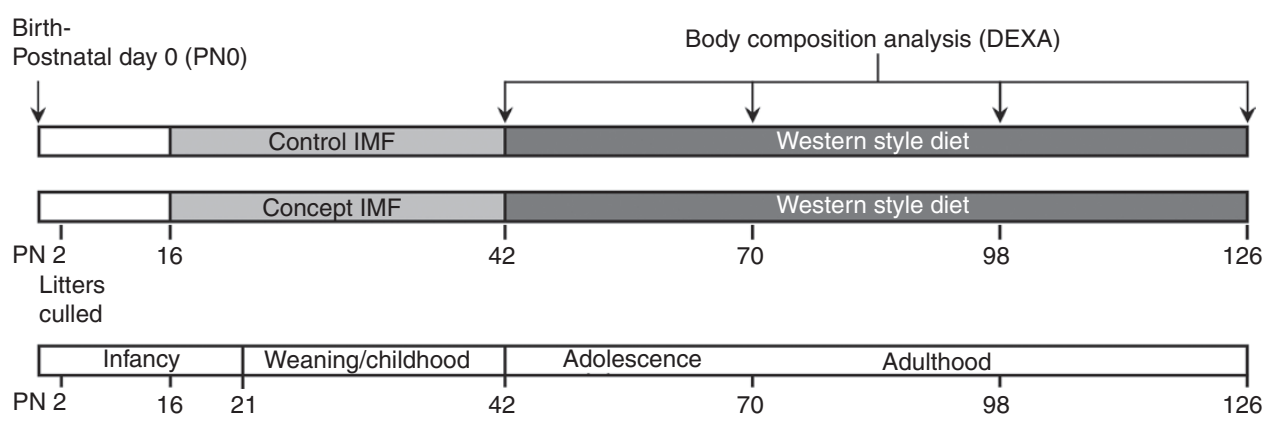

Figure 4. Study design from postnatal day (PN) 0-PN126. DEXA, dual-energy X-ray absorptiometry; IMF, infant milk formula.

\section{IMF Production and Analyses}

The Control IMF was produced according to standard stage I IMF recipe and processing procedure (Danone Research, Wageningen, The Netherlands). The Concept IMF was generated by adding $2 \mathrm{~g} / \mathrm{l} \mathrm{PL}$ of buttermilk serum origin (BAEF powder, Corman Food industry, Goé, Belgium) and adjusted processing to obtain PL-coated lipid droplets larger than those in standard IMF. Briefly, the polar PLs were added to the aqueous phase and blended with the lipid phase containing the neutral vegetable lipids to generate a PL coating around the lipid droplets. Homogenization pressure during processing was reduced to secure a homogeneous mixture of ingredients but also to retain a large lipid droplet size (47).

Lipid droplet size distribution was measured using a Mastersizer laser light-scattering analyzer with a refractive index ratio of 1.46 (Mastersizer 2000, Hydro 2000 G, Malvern Instruments, Worcestershire, UK). In addition, lipid droplets were visualized by laser scanning microscopy (Zeiss Laser Scanning Microscope 510, Axiovert 100M, Carl Zeiss Benelux, Sliedrecht, The Netherlands) to obtain high-resolution images and dual staining of the fat core and PL coating of the lipid droplets (analyses performed at the Centre for Advanced Microscopy of the Swammerdam Institute for Life Sciences at the University of Amsterdam, courtesy of Dr Gadella). The IMFs were reconstituted in a binding buffer $(10 \mathrm{mM}$ HEPES, $140 \mathrm{mmol} / \mathrm{l} \mathrm{NaCl}$, and $2.5 \mathrm{mmol} / \mathrm{l} \mathrm{CaCl}$, $\mathrm{pH}$ 7.4). Subsequently fluorescent Annexin-V Alexa Fluor 488 (Invitrogen Molecular Probes, Bleiswijk, The Netherlands) and Nile Red (Sigma-Aldrich, Zwijndrecht, The Netherlands) probes were added and incubated for at least $5 \mathrm{~min}$ in the dark at room temperature. Twenty five microliters of each sample was spotted into an 8-welled chamber slide. Images of representative areas of each sample were taken using a Zeiss Plan-Neofluar $\times 100$ magnification objective with a numerical aperture of 1.3. The stability of the concept IMF lipid structure was analyzed repeatedly over time and was considered stable for at least $6 \mathrm{mo}$.

\section{Experimental Diets}

All experimental semi-synthetic diets (Research Diet Services, Wijk bij Duurstede, The Netherlands; Table 1) had a macro- and micronutrient composition according to American Institute of Nutrition formulation of AIN93G purified diets for laboratory rodents (48). The postnatal IMF diets contained $28.3 \% \mathrm{w} / \mathrm{w}$ Control or Concept IMF and were complemented with protein and carbohydrates. The moderate WSD consisted of $10 \% \mathrm{w} / \mathrm{w}$ fat $(5 \% \mathrm{w} / \mathrm{w}$ lard and $0.1 \% \mathrm{w} / \mathrm{w}$ cholesterol).

\section{Body Composition Measurements}

On PN42, PN70, PN98, and PN126 FM and LBM were measured by dual-energy X-ray absorptiometry scan under general anesthesia (isoflurane $/ \mathrm{N}_{2} \mathrm{O} / \mathrm{O}_{2}$ ) using a PIXImus imager (GE Lunar, Madison, WI). $\mathrm{FM}$ was also calculated as percentage of BW (\%FM). BW, LBM, FM, and \%FM gain (dBW, dLBM, dFM, and d\%FM, respectively) between PN42 and PN126 was calculated by subtracting PN42 values from PN70, PN98, and PN126 values.

\section{Blood Sampling and Dissection}

On PN126, mice were anesthesized (isoflurane/ $\mathrm{N}_{2} \mathrm{O} / \mathrm{O}_{2}$ ) after $4 \mathrm{~h}$ fasting (from 7:30 AM) during the light phase for final dual-energy $\mathrm{X}$-ray absorptiometry scan and killed with cervical dislocation after blood sampling through heart puncture. Blood samples were collected in $\mathrm{K}_{3}$ EDTA-coated $1 \mathrm{ml}$ microtubes. Plasma was obtained after centrifugation at $1350 \mathrm{~g}$ for $12 \mathrm{~min}$ at $4{ }^{\circ} \mathrm{C}$ and stored at -80 ${ }^{\circ} \mathrm{C}$. Liver, pancreas, musculus tibialis, brain, epididymal, retroperitoneal, and inguinal white adipose tissue depots were dissected and weighed.

\section{Plasma Analyses}

Total adiponectin was determined using a mouse adiponectin enzyme-linked immunosorbent assay kit (Linco Research, Millipore Bioscience, Billerica, MA). Plasma insulin, leptin, monocyte chemoattractant protein 1 , total plasminogen activator inhibitor-1, interleukin 6, tumor necrosis factor $\alpha$, and resistin were measured using a mouse serum adipokine lincoplex kit (Linco Research). Samples, standards, and quality control were prepared according to manufacturers' protocol and fluorescence was measured using a BioPlex 200 Luminex instrument (Bio-Rad Laboratories, Hercules, CA). Fasting plasma TC (liquicolor cholesterol oxidase-phenol aminophenazone method, Instruchemie, Delfzijl, The Netherlands), TG (glycerol phosphate oxidase trinder method; Sigma Aldrich), and glucose (glucose oxidase-phenol aminophenazone method; Roche Diagnostics, Almere, The Netherlands) were measured colorimetrically and analyzed with a microplate imaging system (Bio-Rad Laboratories, Veenendaal, The Netherlands). Homeostasis model assessment of insulin resistance was calculated from fasting plasma glucose and insulin $(\mathrm{glu}(\mathrm{mmol} / \mathrm{l}) \times$ ins $(\mathrm{pmol} / \mathrm{l}) / 22.5)$ as an indirect measure of insulin sensitivity.

\section{Statistical Analysis}

Statistical analyses were performed using SPSS 15.0.1 software (SPSS Benelux, Gorinchem, The Netherlands). Variables were checked for Gaussian distribution with the Shapiro-Wilkes test. Levene's test for equality of variance was used to assess the probability of different variances among treatment groups. Direct effects of experimental diet (Control IMF and Concept IMF) were analyzed by means of Student's $t$-test. Programming effects of experimental diet on development of body composition during WSD were analyzed using a repeated-measures ANOVA. Post hoc analyses were performed on confirmed diet $\times$ time interactions by univariate ANOVA of PN42, PN70, PN98, and PN126, separately. Effects of experimental diets on white adipose tissue weight, organ weight, food intake, and plasma parameters were analyzed by means of Student's $t$-test. Data are presented as mean \pm SEM unless otherwise indicated. Differences were considered significant at $P<0.05$.

\section{STATEMENT OF FINANCIAL SUPPORT}

The study was funded by Danone Research, Centre for Specialised Nutrition.

Disclosure: A.O., D.K., I.C.T., H.J.W., B.J.M.v.d.H., and E.M.v.d.B. are employed by Danone Research. H.J.V. is a consultant for Danone research outside the submitted work, for which his institution is compensated financially.

\section{REFERENCES}

1. Kelly T, Yang W, Chen CS, Reynolds K, He J. Global burden of obesity in 2005 and projections to 2030. Int J Obes (Lond) 2008;32:1431-7. 
2. Jackson-Leach R, Lobstein T. Estimated burden of paediatric obesity and co-morbidities in Europe. Part 1. The increase in the prevalence of child obesity in Europe is itself increasing. Int J Pediatr Obes 2006;1:26-32.

3. Lobstein T, Baur L, Uauy R. Obesity in children and young people: a crisis in public health. Obes Rev 2004;5:Suppl 1:4-104.

4. Arenz S, Rückerl R, Koletzko B, von Kries R. Breast-feeding and childhood obesity-a systematic review. Int J Obes Relat Metab Disord 2004;28: 1247-56.

5. Harder T, Bergmann R, Kallischnigg G, Plagemann A. Duration of breastfeeding and risk of overweight: a meta-analysis. Am J Epidemiol 2005;162:397-403.

6. Durmus B, Mook-Kanamori DO, Holzhauer S, et al. Growth in foetal life and infancy is associated with abdominal adiposity at the age of 2 years: the generation R study. Clin Endocrinol (Oxf) 2010;72:633-40.

7. Demerath EW, Reed D, Choh AC, et al. Rapid postnatal weight gain and visceral adiposity in adulthood: the Fels Longitudinal Study. Obesity (Silver Spring) 2009;17:2060-6.

8. Dewey KG, Heinig MJ, Nommsen LA, Peerson JM, Lönnerdal B. Breastfed infants are leaner than formula-fed infants at $1 \mathrm{y}$ of age: the DARLING study. Am J Clin Nutr 1993;57:140-5.

9. Nommsen-Rivers LA, Dewey KG. Growth of breastfed infants. Breastfeed Med 2009;4:Suppl 1:S45-9.

10. Agostoni C. Ghrelin, leptin and the neurometabolic axis of breastfed and formula-fed infants. Acta Paediatr 2005;94:523-5.

11. Lönnerdal B. Nutritional and physiologic significance of human milk proteins. Am J Clin Nutr 2003;77:1537S-43S.

12. Field CJ. The immunological components of human milk and their effect on immune development in infants. J Nutr 2005;135:1-4.

13. Innis SM. Human milk: maternal dietary lipids and infant development. Proc Nutr Soc 2007;66:397-404.

14. Jensen RG, Ferris AM, Lammi-Keefe CJ. Lipids in human milk and infant formulas. Annu Rev Nutr 1992;12:417-41.

15. SmitEN,MartiniIA,KempermanRF,SchaafsmaA,MuskietFA,BoersmaER. Fatty acids in formulae for term infants: compliance of present recommendations with the actual human milk fatty acid composition of geographically different populations. Acta Paediatr 2003;92:790-6.

16. Michalski MC, Briard V, Michel F, Tasson F, Poulain P. Size distribution of fat globules in human colostrum, breast milk, and infant formula. J Dairy Sci 2005;88:1927-40.

17. Koletzko B, Rodriguez-Palmero M, Demmelmair H, Fidler N, Jensen R, Sauerwald T. Physiological aspects of human milk lipids. Early Hum Dev 2001;65:Suppl:S3-S18.

18. Oosting A, Kegler D, Boehm G, Jansen HT, van de Heijning BJ, van der Beek EM. N-3 long-chain polyunsaturated fatty acids prevent excessive fat deposition in adulthood in a mouse model of postnatal nutritional programming. Pediatr Res 2010;68:494-9.

19. Going SB, Lohman TG, Cussler EC, Williams DP, Morrison JA, Horn PS. Percent body fat and chronic disease risk factors in U.S. children and youth. Am J Prev Med 2011;41(4 Suppl 2):S77-86.

20. Cepeda-Valery B, Pressman GS, Figueredo VM, Romero-Corral A. Impact of obesity on total and cardiovascular mortality-fat or fiction? Nat Rev Cardiol 2011;8:233-7.

21. Murer SB, Knöpfli BH, Aeberli I, et al. Baseline leptin and leptin reduction predict improvements in metabolic variables and long-term fat loss in obese children and adolescents: a prospective study of an inpatient weightloss program. Am J Clin Nutr 2011;93:695-702.

22. Mikirova NA, Casciari JJ, Hunninghake RE, Beezley MM. Effect of weight reduction on cardiovascular risk factors and CD34-positive cells in circulation. Int J Med Sci 2011;8:445-52.

23. Symonds ME, Gardner DS. Experimental evidence for early nutritional programming of later health in animals. Curr Opin Clin Nutr Metab Care 2006;9:278-83.

24. Garg M, Thamotharan M, Oak SA, et al. Early exercise regimen improves insulin sensitivity in the intrauterine growth-restricted adult female rat offspring. Am J Physiol Endocrinol Metab 2009;296:E272-81.

25. Oak S, Tran C, Castillo MO, Thamotharan S, Thamotharan M, Devaskar SU. Peroxisome proliferator-activated receptor-gamma agonist improves skeletal muscle insulin signaling in the pregestational intrauterine growth-restricted rat offspring. Am J Physiol Endocrinol Metab 2009;297: E514-24.

26. Wyrwoll CS, Mark PJ, Mori TA, Puddey IB, Waddell BJ. Prevention of programmed hyperleptinemia and hypertension by postnatal dietary omega-3 fatty acids. Endocrinology 2006;147:599-606.

27. Wyrwoll CS, Mark PJ, Mori TA, Waddell BJ. Developmental programming of adult hyperinsulinemia, increased proinflammatory cytokine production, and altered skeletal muscle expression of SLC2A4 (GLUT4) and uncoupling protein 3. J Endocrinol 2008;198:571-9.

28. Siemelink M, Verhoef A, Dormans JA, Span PN, Piersma AH. Dietary fatty acid composition during pregnancy and lactation in the rat programs growth and glucose metabolism in the offspring. Diabetologia 2002;45:1397-403.

29. Srinivasan M, Mitrani P, Sadhanandan G, et al. A high-carbohydrate diet in the immediate postnatal life of rats induces adaptations predisposing to adult-onset obesity. J Endocrinol 2008;197:565-74.

30. Ibáñez L, Ong K, Dunger DB, de Zegher F. Early development of adiposity and insulin resistance after catch-up weight gain in small-for-gestational-age children. J Clin Endocrinol Metab 2006;91:2153-8.

31. Ong KK, Emmett P, Northstone K, et al. Infancy weight gain predicts childhood body fat and age at menarche in girls. J Clin Endocrinol Metab 2009;94:1527-32.

32. Waterland RA, Garza C. Early postnatal nutrition determines adult pancreatic glucose-responsive insulin secretion and islet gene expression in rats. J Nutr 2002;132:357-64.

33. Chamson-Reig A, Thyssen SM, Hill DJ, Arany E. Exposure of the pregnant rat to low protein diet causes impaired glucose homeostasis in the young adult offspring by different mechanisms in males and females. Exp Biol Med (Maywood) 2009;234:1425-36.

34. Spalding KL, Arner E, Westermark PO, et al. Dynamics of fat cell turnover in humans. Nature 2008;453:783-7.

35. Amri EZ, Ailhaud G, Grimaldi PA. Fatty acids as signal transducing molecules: involvement in the differentiation of preadipose to adipose cells. J Lipid Res 1994;35:930-7.

36. Mott GE, Lewis DS, McMahan CA. Infant diet affects serum lipoprotein concentrations and cholesterol esterifying enzymes in baboons. J Nutr 1993;123:155-63.

37. Wong WW, Hachey DL, Insull W, Opekun AR, Klein PD. Effect of dietary cholesterol on cholesterol synthesis in breast-fed and formula-fed infants. J Lipid Res 1993;34:1403-11.

38. Vickers MH, Guan J, Gustavsson M, et al. Supplementation with a mixture of complex lipids derived from milk to growing rats results in improvements in parameters related to growth and cognition. Nutr Res 2009;29:426-35.

39. Armand M, Pasquier B, André M, et al. Digestion and absorption of 2 fat emulsions with different droplet sizes in the human digestive tract. Am J Clin Nutr 1999;70:1096-106.

40. Armand M, Hamosh M, Mehta NR, et al. Effect of human milk or formula on gastric function and fat digestion in the premature infant. Pediatr Res 1996;40:429-37.

41. Michalski MC, Soares AF, Lopez C, Leconte N, Briard V, Geloen A. The supramolecular structure of milk fat influences plasma triacylglycerols and fatty acid profile in the rat. Eur J Nutr 2006;45:215-24.

42. Michalski MC, Briard V, Desage M, Geloen A. The dispersion state of milk fat influences triglyceride metabolism in the rat-a $13 \mathrm{CO} 2$ breath test study. Eur J Nutr 2005;44:436-44.

43. Guo J, Jou W, Gavrilova O, Hall KD. Persistent diet-induced obesity in male C57BL/6 mice resulting from temporary obesigenic diets. PLoS ONE 2009;4:e5370.

44. Howie GJ, Sloboda DM, Kamal T, Vickers MH. Maternal nutritional history predicts obesity in adult offspring independent of postnatal diet. J Physiol (Lond) 2009;587(Pt 4):905-15.

45. van Schothorst EM, Bunschoten A, Verlinde E, Schrauwen P, Keijer J. Glycemic index differences of high-fat diets modulate primarily lipid metabolism in murine adipose tissue. Physiol Genomics 2011;43:942-9. 
46. Balagopal PB, de Ferranti SD, Cook S, et al. Nontraditional risk factors and biomarkers for cardiovascular disease: mechanistic, research, and clinical considerations for youth: a scientific statement from the American Heart Association. Circulation 2011;123:2749-69.

47. van Baalen A, Van Der Beek E, Beermann C, Boehm G, inventors; NUTRICIA, N.V., assignee. Nutritional compositions with lipid globules with a core comprising vegetable lipids and a coating comprising phospholipids or polar lipids. WO patent, 11 March 2010.

48. Reeves PG, Nielsen FH, Fahey GC Jr. AIN-93 purified diets for laboratory rodents: final report of the American Institute of Nutrition ad hoc writing committee on the reformulation of the AIN-76A rodent diet. J Nutr 1993;123:1939-51. 